REVISTA INTERNACIONAL DE CIENCIAS DEL DEPORTE International Journal of Sport Science

Rev. int. cienc. deporte

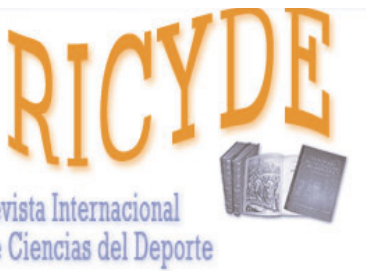

International Journal of Sport Science VOLUMEN X - AÑO X

Páginas:95-108 ISSN:1885-3137

No 36 - Abril - 2014

\title{
Influence of the biomechanical variables of the gait cycle in running economy \\ Influencia de variables biomecánicas del ciclo de paso en la economía de carrera
}

Santos-Concejero, J.1,2, Granados, C.2, Irazusta, J.3, Bidaurrazaga-Letona, I. ${ }^{2}$ Zabala-Lili, J.2, Tam, N.1, \& Gil, S.M.2

1.Department of Human Biology. University of Cape Town. South Africa

2.Department of Physical Education and Sport. University of the Basque Country UPV/EHU. Spain

3.Department of Physiology. University of the Basque Country UPV/EHU. Spain

\begin{abstract}
The aim of this study was to investigate the relationships between biomechanical variables and running economy (RE). Eleven recreational (RR) and 14 well-trained runners (WT) completed 4 min stages on a treadmill at different speeds. During the test, biomechanical variables such as ground contact time (tc), swing time (tsw), stride length, frequency and angle and the length of the different subphases of ground contact were calculated using an optical measurement system. VO2 was measured in order to calculate RE. The WT runners were more economical than the RR at all speeds and presented lower tc, higher tsw, longer strides, lower stride frequencies and higher stride angles $(P<0.05)$. Similarly, the WT runners experienced a later propulsion subphase than the RR runners $(P<0.05)$. RE was positively related to tc, stride frequency and $10-\mathrm{km}$ race pace, whereas it was negatively related to tsw, stride length, stride angle and the propulsive subphase. Our results suggest that running patterns characterized by longer stride lengths and higher stride angles, lower stride frequencies and tc, higher tsw and later propulsion suphases may enable an efficient energy use per stride.
\end{abstract}

Key words: ground contact; stride angle; swing time; stride length; stride frequency.

\section{Resumen}

El objetivo de este estudio fue el investigar las relaciones entre diferentes variables biomecánicas y la economía de carrera (RE). Once atletas populares (RR) y 14 atletas altamente entrenados (WT) completaron estadios de $4 \mathrm{~min}$ en tapiz rodante a diferentes velocidades. Durante el test, el tiempo de contacto (tc) y de vuelo (tsw), la longitud, frecuencia y ángulo de zancada y la duración de las diferentes sub-fases del tiempo de contacto se calcularon usando un sistema óptico. Se midió el VO2 para calcular la RE. Los atletas WT fueron más económicos que los RR y presentaron menores tc, mayores tsw, zancadas más largas, frecuencias más bajas y ángulos mayores $(P<0.05)$. Además, los atletas WT experimentaron la sub-fase propulsiva más tarde que los $\mathrm{RR}(\mathrm{P}<0.05)$. La RE estuvo positivamente relacionada con el tc, la frecuencia de zancada y el ritmo de $10 \mathrm{~km}$, mientras que estuvo negativamente relacionada con el tsw, longitud y ángulo de zancada y la sub-fase propulsiva. Estos resultados sugieren que una biomecánica caracterizada por zancadas más largas, ángulos de zancada y tsw mayores, menores frecuencias y tc, y sub-fases propulsivas más tardías pueden favorecer un uso energético más eficiente.

Palabras clave: tiempo de contacto; ángulo de zancada; tiempo de vuelo; longitud de zancada; frecuencia de zancada.

Correspondence/correspondencia: Jordan Santos Concejero

Department of Human Biology. University of Cape Town. Sudáfrica

Email: jsantosconcejero@gmail.com 
Santos-Concejero, J.; Granados, C.; Irazusta, J., Bidaurrazaga-Letona, I.; Zabala-Lili, J.; Tam, N., \& Gil, S.M. (2014). Influence of the biomechanical variables of the gait cycle in running economy. RICYDE. Revista internacional de ciencias del deporte, 36(10), 95-108 http://dx.doi.org/10.5232/ricyde2014.03601

\section{Introduction}

Qustained running performance is reliant on a complex interaction of factors that lead to Sefficient muscular work and should result in fast and effective running gait (Joyner, 1991). Historically, physiological factors such as cardiac output, oxygen delivery to working muscles and maximal oxygen uptake $\left(V \mathrm{O}_{2 \max }\right)$ have been thoroughly researched as predictors of exercise performance (Nummela, Keränen \& Mikkelsson, 2007). These predictors reveal certain aspects to elite- and world-class performance and are able to distinctively identify discrepancies between untrained and well-trained groups. However, the ability to unravel the difference between these well-trained homogenous groups is more challenging (Levine, 2008).

Since the 1970s running economy (RE) has been investigated, although it is often still referred to as "being relatively ignored in the scientific literature" (Foster \& Lucia, 2007). When working with well-trained homogenous groups and East African runners, RE has been found to most appropriately discriminate between their performances (Lucia et al., 2006; Pate, Macera, Bailey, Bartoli \& Powell, 1992). Consequently, RE is considered, together with $V \mathrm{O}_{2 \max }$ and the lactate threshold, as an important factor related to distance running success (Conley \& Krahenbuhl, 1980; Di Prampero, Atchou, Brückner \& Moia, 1986).

$\mathrm{RE}$ is commonly defined as the steady-state oxygen uptake $\left(V \mathrm{O}_{2}\right)$ required at a given submaximal speed (Cavanagh \& Williams, 1982; Karp, 2010; Nummela et al., 2007) or as the energy requirement per distance (Di Pampero et al., 1986; Helgerud, Engen, Wisloff \& Hoff, 2001). It can also be expressed as the percentage of the maximal oxygen uptake utilized $\left(\% V \mathrm{O}_{2 \max }\right)$ (Conley \& Krahenbuhl, 1980) or as mechanical efficiency, which is the ratio between work output and oxygen cost (Åstrand, Rodahl, Dahl \& Strommer, 1986).

Several studies have reported inter-individual variations in RE (Conley \& Krahenbuhl, 1980), which reflects its importance in running performance (Helgerud, Støren \& Hoff, 2010). Physiological factors (Mayhew, 1997), muscle fiber distribution (Bosco et al., 1987), age (Krahenbuhl \& Pangrazi, 1983), sex (Bransford \& Howley, 1987) and anthropometric factors (Bergh, Sjödin, Forsberg \& Svedenhag, 1991) have also been proposed to explain the interindividual variability in RE.

$\mathrm{RE}$ is also influenced by biomechanical variables, largely attributed to ground contact characteristics (Chapman, Laymon, Wilhite, McKenzie, Tanner \& Stager, 2011; Kyröläinen, Belli \& Komi, 2001). Shorter ground contact times are correlated with a higher $V \mathrm{O}_{2}$ (Kram \& Taylor, 1990), whereas small vertical oscillations (Gregor \& Kirkendall, 1978), longer strides (Tartaruga et al., 2012), smaller changes in speed during ground contact (Kaneko, Ito, Fuchimoto, Shishikura \& Toyooka, 1985) and lower peak ground reaction forces (Anderson, 1996) have been related to economical runners.

Increasing relative running speeds have been found to influence an athlete's RE (Daniels \& Daniels, 1992). For example, elite middle-distance runners have efficient RE at speeds above or at marathon pace, and less efficient RE below marathon pace when compared to longdistance runners (Daniels \& Daniels, 1992). It appears that runners with different training specializations have multiple factors influencing their RE and may be a possible reason for inconsistent findings (Di Prampero et al., 1986).

At present, the response of $\mathrm{RE}$ at different exercise intensities is not well understood. Fast running speeds may be a result of higher vertical ground reaction forces whilst minimizing the ground contact time of the foot (Weyand, Sternlight, Bellizzi \& Wright, 2000). However, a shorter ground contact time has been shown to correlate with a higher mass-specific 
Santos-Concejero, J.; Granados, C.; Irazusta, J., Bidaurrazaga-Letona, I.; Zabala-Lili, J.; Tam, N., \& Gil, S.M. (2014). Influence of the biomechanical variables of the gait cycle in running economy. RICYDE. Revista internacional de ciencias del deporte, 36(10), 95-108 http://dx.doi.org/10.5232/ricyde2014.03601

metabolic cost of running (Kram \& Taylor, 1990). Therefore, it may be inferred that runners must find a way to increase their speed for the distance being raced with longer contact times to minimize the metabolic cost of running.

To date, the influence of biomechanical variables on metabolic cost of running between runners of different athletic ability at different speeds remains unclear. Thus, the purpose of this study was to investigate the influence of biomechanical variables, such as ground contact time, swing time, stride length and frequency, stride angle and the distribution of the different subphases during the ground contact on RE in recreational and well-trained runners.

\section{Methods}

Participants. Eleven recreational (mean \pm SD: age $38.5 \pm 4.0$ years, height $176.9 \pm 6.9 \mathrm{~cm}$,) and 14 well-trained male long distance runners (mean \pm SD: age $27.9 \pm 6.4$ years, height $176.7 \pm 5.3 \mathrm{~cm}$ ) took part in this study. Before participation, all athletes underwent a medical examination to ensure that they were free of cardiovascular, musculoskeletal and metabolic disease. The Ethics Committee for research on Human subjects of the University of the Basque Country (CEISH/GIEB) approved this study, which was performed in accordance with the principles of the Declaration of Helsinki (October 2008, Seoul). All athletes were informed about all the tests and possible risks involved and provided a written informed consent before testing.

Performance was rated according to the runners' recent $10-\mathrm{km}$ personal best time. Inclusion criteria in the well-trained group was current participation in national or international level competitions and a $10-\mathrm{km}$ race time $<33.5 \mathrm{~min}$. The recreational group trained a minimum of three days a week of running sessions and a $10-\mathrm{km}$ race time $>35 \mathrm{~min}$. None of the recreational runners had an athletics license from any athletics federation.

Twenty-four hours prior to testing, athletes were encouraged to abstain from a hard training session and competition in order to be well rested for the tests. They were also requested to maintain their pre-competition diets throughout the test procedures. All athletes had previous experience with treadmill running, including a thorough familiarization session with the treadmill used for the study.

Anthropometry. Height $(\mathrm{cm})$ and body mass $(\mathrm{kg})$ were determined by the use of a precision stadiometer and balance (Seca, Bonn, Germany) and body mass index (BMI) was then determined. All measurements were taken with the participants wearing only running shorts. Eight skinfold sites (biceps, triceps, subscapular, supraspinale, abdominal, suprailiac, midthigh, and medial calf) were measured in duplicate with skinfold calipers (Holtain, Crymych, UK) by the same researcher to the nearest millimeter and the skinfold sum was calculated. Body fat percentage $(\% \mathrm{BF})$ was calculated for each athlete as previously described (Yuhasz, 1974).

Treadmill speed test. All participants completed a maximal incremental running test at $1 \%$ slope on a treadmill (ERGelek EG2, Vitoria-Gasteiz, Spain), which started at $9 \mathrm{~km} \cdot \mathrm{h}^{-1}$ without previous warm up. The speed was increased by $1.5 \mathrm{~km} \cdot \mathrm{h}^{-1}$ every $4 \mathrm{~min}$ until volitional exhaustion, with a minute of recovery between each stage (Yoshida, 1984; Maldonado, Mujika \& Padilla, 2002; Maldonado-Martín, Mujika \& Padilla, 2004). The treadmill was calibrated using a measuring wheel (ERGelek, Vitoria-Gasteiz, Spain) with a measurement error $<0.5 \mathrm{~m}$ per $100 \mathrm{~m}$ interval. All testing sessions were performed under similar environmental conditions $\left(20-24{ }^{\circ} \mathrm{C}, 45-55 \%\right.$ relative humidity). 
Santos-Concejero, J.; Granados, C.; Irazusta, J., Bidaurrazaga-Letona, I.; Zabala-Lili, J.; Tam, N., \& Gil, S.M. (2014). Influence of the biomechanical variables of the gait cycle in running economy. RICYDE. Revista internacional de ciencias del deporte, 36(10), 95-108 http://dx.doi.org/10.5232/ricyde2014.03601

During the test, respiratory variables were continuously measured using a gas analyzer system (Ergocard, Medisoft, Sorinnes, Belgium) calibrated before each session. Volume calibration was performed at different flow rates with a $3 \mathrm{~L}$ calibration syringe (Medisoft, Sorinnes, Belgium) allowing an error $\leq 2 \%$, and gas calibration was performed automatically by the system using both ambient and reference gases $\left(\mathrm{CO}_{2} 4.10 \% ; \mathrm{O}_{2} 15.92 \%\right)$ (Linde Gas, Germany). $V \mathrm{O}_{2}$ data collected during the last $30 \mathrm{~s}$ of each workload under the lactate threshold was averaged and designated as the steady-state value for data analysis. RE was defined as steady-state $V \mathrm{O}_{2}$ per distance covered $\left(\mathrm{ml} \cdot \mathrm{kg}^{-1} \cdot \mathrm{km}^{-1}\right)$ and $V \mathrm{O}_{2}$ was also normalized per $\mathrm{kg}^{0.75}$ to reduce the influence of body mass (Helgerud et al., 2010). Heart rate (HR) was recorded continuously by a heart rate monitor (Polar RS800, Kempele, Finland).

Runners were considered to have attained their $V \mathrm{O}_{2 \max }$ when two of the following criteria were fulfilled: 1) a plateau in $\mathrm{VO}_{2} ; 2$ ) $\mathrm{HR}$ within 5 beats $\cdot \mathrm{min}^{-1}$ of theoretical maximal $\mathrm{HR}$ (220-age) 3); Respiratory exchange ratio (RER) $>1.15$

Peak treadmill speed (PTS; in $\mathrm{km} \cdot \mathrm{h}^{-1}$ ) was calculated as follows taking every second into account:

$\mathrm{PTS}=$ Completed full intensity $\left(\mathrm{km} \cdot \mathrm{h}^{-1}\right)+\left[\left(\right.\right.$ seconds at final speed $\left.\left.\cdot 240 \mathrm{~s}^{-1}\right) \cdot 1.5 \mathrm{~km} \cdot \mathrm{h}^{-1}\right]$

Determination of lactate threshold. Immediately after each exercise stage, capillary blood samples from the earlobe were obtained and lactate concentrations were determined with the use of a portable lactate analyzer (Lactate Pro, Arkray, KDK Corporation, Kyoto, Japan.). This system has been previously validated (Tanner, Fuller \& Ross, 2010). The lactate threshold was determined for each participant from the blood lactate concentrations and speed data obtained during the treadmill speed test. A third order polynomial regression equation was calculated with the plasma lactate concentrations versus speed. The lactate threshold was identified as the point on the polynomial regression curve that yielded the maximal distance to the straight line formed by the two end data points (Cheng, Kuipers, Snyder, Keizer, Jeukendrup \& Hesselink, 1992).

\section{Biomechanics}

Stride angle, ground contact time, swing time and stride length and frequency were measured for every step during the treadmill speed test using an optical measurement system (Optojump-next, Microgate, Bolzano, Italy). The values of minutes 2 and 3 of each workload where averaged and used for data analysis. This system is developed to measure with $1 \mathrm{kHz}$ precision all flying and ground contact times while running. Optojump-next system consists of two bars (size $100 \mathrm{~cm} \times 3 \mathrm{~cm} \times 4 \mathrm{~cm}$ ), one containing the reception and control unit, the other embedding the transmission electronics. Each of these contains 32 light emitting diodes (LEDs), positioned $0.3 \mathrm{~cm}$ from ground level at $3.125 \mathrm{~cm}$ intervals. The LEDs on the transmitting bar communicate continuously $(1 \mathrm{kHz})$ with those on the receiving bar.

Ground contact time was defined as the time from when the foot contacts the ground to when the foot toes off the ground and was determined by the disruption of the infrared gates of the Optojump-next system. Using the same principle, swing time was defined as the time from toe off to initial ground contact of consecutive footfalls of the same foot. Stride length and stride frequency were defined as the length the treadmill belt moves from toe off to initial ground contact in successive steps and as the number of ground contact events per minute, respectively. The Optojump-next system has been shown to determine accurately these variables before (Debaere, Jonkers \& Delecluse, 2013). 


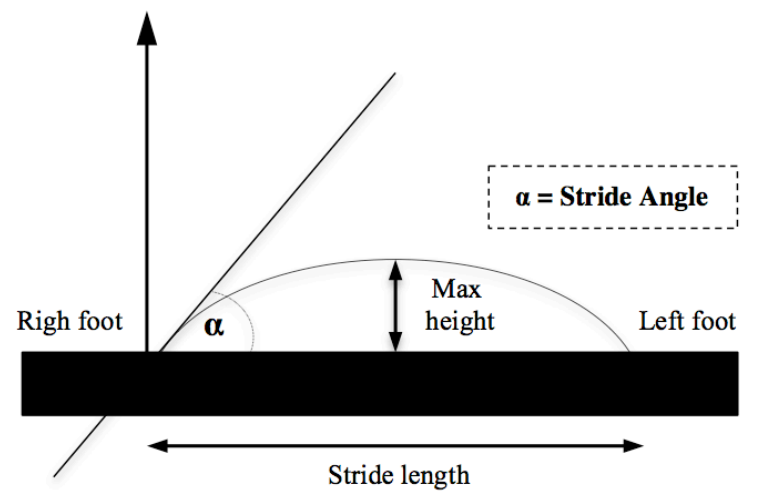

Figure 1. Schematic representation of the stride angle measured by the Optojump-next system.

Stride angle was defined as the angle of the parabola tangent derived from the theoretical arc traced by a foot during a stride and the ground (Figure 1). The theoretical parabola for the stride angle determination was calculated by the Optojump-next system through the stride length and the maximal height of the foot during a stride.

Lastly, the percentage of the ground contact time at which the different subphases of stance phase occurs (initial contact, midstance and propulsion) was also measured for every step during the treadmill speed test automatically by the Optojump-next system. During the stance phase of the gait cycle, the initial contact subphase corresponds to the time from initial ground contact to foot flat; midstance subphase from foot flat to initial take off and propulsive subphase from initial take off to toe off. The coefficient of variation of the variables measured with the Optojump-next ranged from 1.0 to $7.6 \%$ (author`s unpublished data).

Statistics. All values are expressed as mean \pm standard deviation (SD) and statistical analyses of data were performed using the Statistical Package for the Social Sciences 15.0 software package (StatSoft, Tulsa, OK, USA). Data were screened for normality of distribution and homogeneity of variances using a Shapiro-Wilk normality test and a Levene's test respectively. An independent Student t-test was used to determine differences between the groups at the set running speeds. In cases where variables were not normally distributed, a Mann-Whitney U-test was utilized. Pearson and Spearman correlations assessed relationships between variables.

The magnitude of differences or effect size (ES) were calculated for significant differences according to Cohen (1998) and interpreted as small $(>0.2$ and $<0.6)$, moderate $(\geq 0.6$ and $<1.2)$, large $(\geq 1.2$ and $<2)$ and very large $(\geq 2$ and $<4)$ according to the scale proposed by Hopkins, Marshall, Batterham and Hanin (2009). Significance for all analyses was set at $P<0.05$.

\section{Results}

Descriptive characteristics and maximal treadmill test results of both recreational and welltrained runners are listed in Table 1. The well-trained runners were younger and faster according to their best 10 -km time than the recreational runners $(P<0.001$, very large ES). The well-trained runners were lighter, and presented lower BMI values, sum of skinfolds and $\% \mathrm{BF}$ than the recreational runners $(P<0.05$; moderate and large $\mathrm{ES})$.

Further, the well-trained runners achieved a higher PTS $(P<0.001$, very large ES) and a higher $V \mathrm{O}_{2 \max }$ than the recreational runners $(P<0.05$, moderate ES). There were no significant differences in other any maximum physiological variables, such as $\mathrm{HR}_{\max }$ or $\mathrm{RER}_{\max }$ between the two groups (Table 1). 
Santos-Concejero, J.; Granados, C.; Irazusta, J., Bidaurrazaga-Letona, I.; Zabala-Lili, J.; Tam, N., \& Gil, S.M. (2014). Influence of the biomechanical variables of the gait cycle in running economy. RICYDE. Revista internacional de ciencias del deporte, 36(10), 95-108 http://dx.doi.org/10.5232/ricyde2014.03601

Table 1. Subject characteristics and maximal test results of the recreational and well-trained runners.

\begin{tabular}{lccc}
\hline & Recreational & Well-trained & Effect sizes \\
& $(n=11)$ & $(n=14)$ & \\
\hline Age $($ years $)$ & $38.5 \pm 4.0$ & $27.9 \pm 6.4^{* * *}$ & 1.98 \\
PTS $\left(\mathrm{km} \cdot \mathrm{h}^{-1}\right)$ & $17.8 \pm 1.7$ & $21.7 \pm 1.1^{* * *}$ & 2.72 \\
$10-\mathrm{km} \mathrm{race} \mathrm{time}(\mathrm{min})$ & $38.9 \pm 3.2$ & $31.7 \pm 1.4^{* * *}$ & 2.96 \\
Height $(\mathrm{cm})$ & $176.8 \pm 6.9$ & $176.7 \pm 5.3$ & 0.01 \\
Mass $(\mathrm{kg})$ & $69.6 \pm 7.4$ & $64.7 \pm 3.9^{*}$ & 0.82 \\
$\mathrm{BMI}^{*}$ & $22.2 \pm 1.8$ & $20.8 \pm 1.4^{*}$ & 0.86 \\
$\sum 8$ skinfold $\left(\mathrm{mm}^{*}\right)$ & $70.7 \pm 23.3$ & $46.6 \pm 12.0^{* *}$ & 1.30 \\
$\sum 6$ skinfold $(\mathrm{mm})$ & $60.3 \pm 19.5$ & $39.2 \pm 10.7^{* *}$ & 1.34 \\
\%BF & $12.0 \pm 2.5$ & $9.5 \pm 0.9^{* *}$ & 1.33 \\
$V \mathrm{O}_{2 \text { peak }}\left(\mathrm{ml} \cdot \mathrm{kg}^{-1} \cdot \mathrm{min}^{-1}\right)$ & $63.9 \pm 7.1$ & $69.5 \pm 3.4^{*}$ & 1.00 \\
$\mathrm{HR}_{\text {max }}\left(\mathrm{beats} \cdot \mathrm{min}^{-1}\right)$ & $183.4 \pm 6.9$ & $187.1 \pm 5.8$ & 0.58 \\
$\mathrm{RER}_{\text {max }}$ & $1.19 \pm 0.08$ & $1.21 \pm 0.06$ & 0.28 \\
\hline
\end{tabular}

$n$, number of participants; PTS, peak treadmill speed; BMI, body mass index, $\sum 8$ skinfolds, biceps, triceps, subscapular, supraspinale, abdominal, suprailiac, mid-thigh, and medial calf; $\sum 6$ skinfolds, triceps, subscapular, abdominal, suprailiac, mid-thigh, and medial calf; $\% \mathrm{BF}$, percentage of body fat; $V \mathrm{O}_{2 \text { peak }}$, maximum oxygen uptake rate; $\mathrm{HR}_{\max }$, maximum heart rate; $\mathrm{RER}_{\max }$, maximum respiratory exchange ratio. Values are means $\pm \mathrm{SD}$. Significantly different when compared to recreational runners: ${ }^{*} P<0.05 ;{ }^{* *} P<0.01 ;{ }^{* * *} P<0.001$

The well-trained runners were significantly more economical than their recreational counterparts according $\mathrm{VO}_{2}$ (relative to body mass and relative to body mass ${ }^{0.75}$ ) and the oxygen cost of running per distance $\left(\mathrm{ml} \cdot \mathrm{kg}^{-1} \cdot \mathrm{km}^{-1}\right)$ at $9 \mathrm{~km} \cdot \mathrm{h}^{-1}, 10.5 \mathrm{~km} \cdot \mathrm{h}^{-1}, 12 \mathrm{~km} \cdot \mathrm{h}^{-1}$ $(P<0.05$; moderate ES $), 13.5 \mathrm{~km} \cdot \mathrm{h}^{-1}(P<0.01$, large ES $)$ and $15 \mathrm{~km} \cdot \mathrm{h}^{-1}(P<0.05$, moderate ES $)$ (Figure 2). 


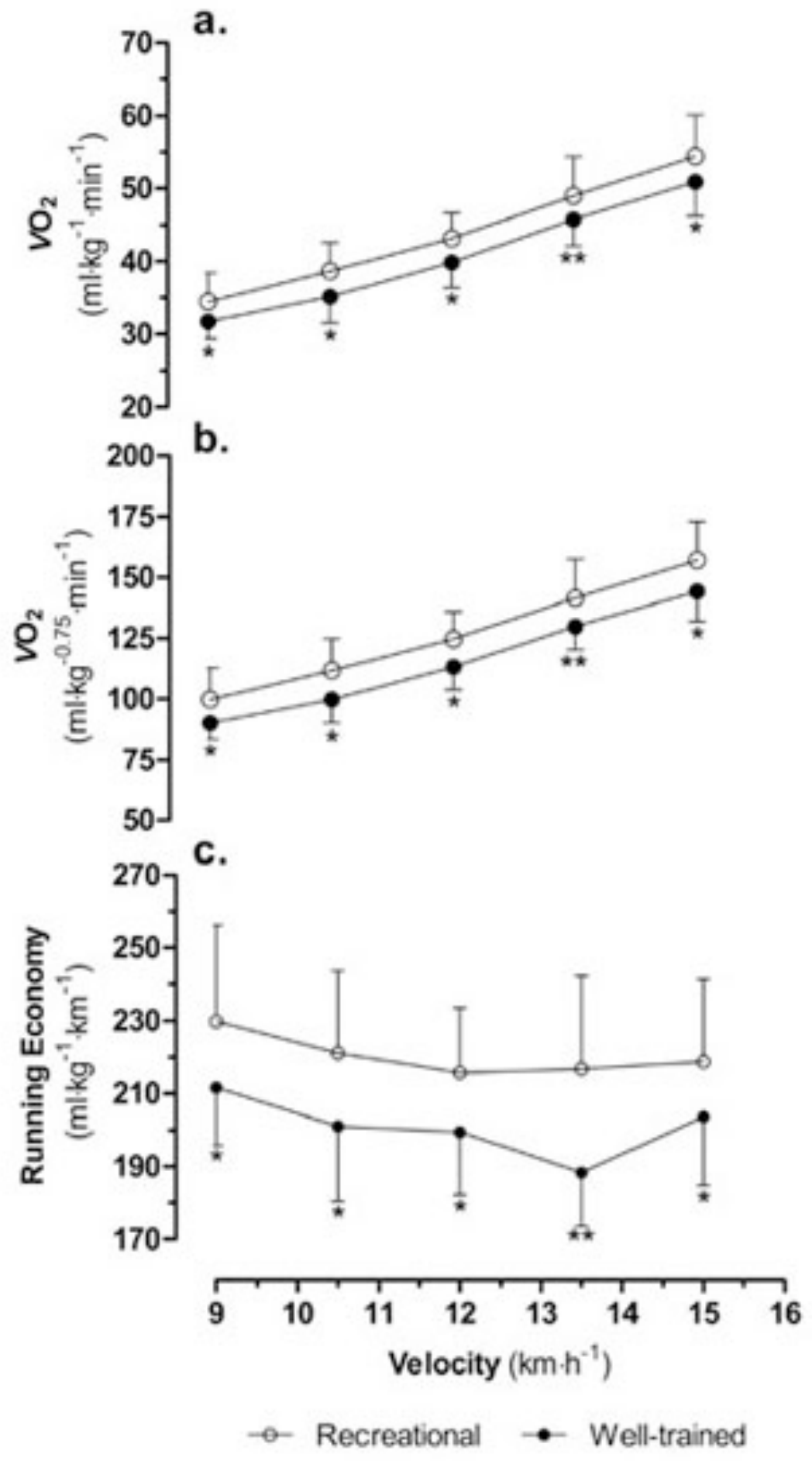

Figure 2. Oxygen uptake $\left(V \mathrm{O}_{2}\right)$ relative to body mass and to body mass ${ }^{0.75}$ and running economy values measured in the recreational and the well-trained runners at different speeds. Significantly different when compared to recreational runners: ${ }^{*} P<0.05 ;{ }^{* *} P<0.01$

Biomechanically, the recreational runners presented higher $t_{\mathrm{c}}$ at $12 \mathrm{~km} \cdot \mathrm{h}^{-1}, 13.5 \mathrm{~km} \cdot \mathrm{h}^{-1}$ $\left(P<0.05\right.$, moderate ES) and $15 \mathrm{~km} \cdot \mathrm{h}^{-1}\left(P<0.01\right.$, large ES) and lower $t_{\mathrm{sw}}$ at $10.5 \mathrm{~km} \cdot \mathrm{h}^{-1}$ $\left(P<0.05\right.$, moderate ES), $12 \mathrm{~km} \cdot \mathrm{h}^{-1}, 13.5 \mathrm{~km} \cdot \mathrm{h}^{-1}$ and $15 \mathrm{~km} \cdot \mathrm{h}^{-1}(P<0.01$, large ES) than the well-trained runners. Similarly, the recreational group experienced earlier propulsion subphase than the well-trained group during ground contact at $10.5 \mathrm{~km} \cdot \mathrm{h}^{-1}, 12 \mathrm{~km} \cdot \mathrm{h}^{-1}$ and $13.5 \mathrm{~km} \cdot \mathrm{h}^{-1}(P<0.05$, moderate ES) (Figure 3$)$. 

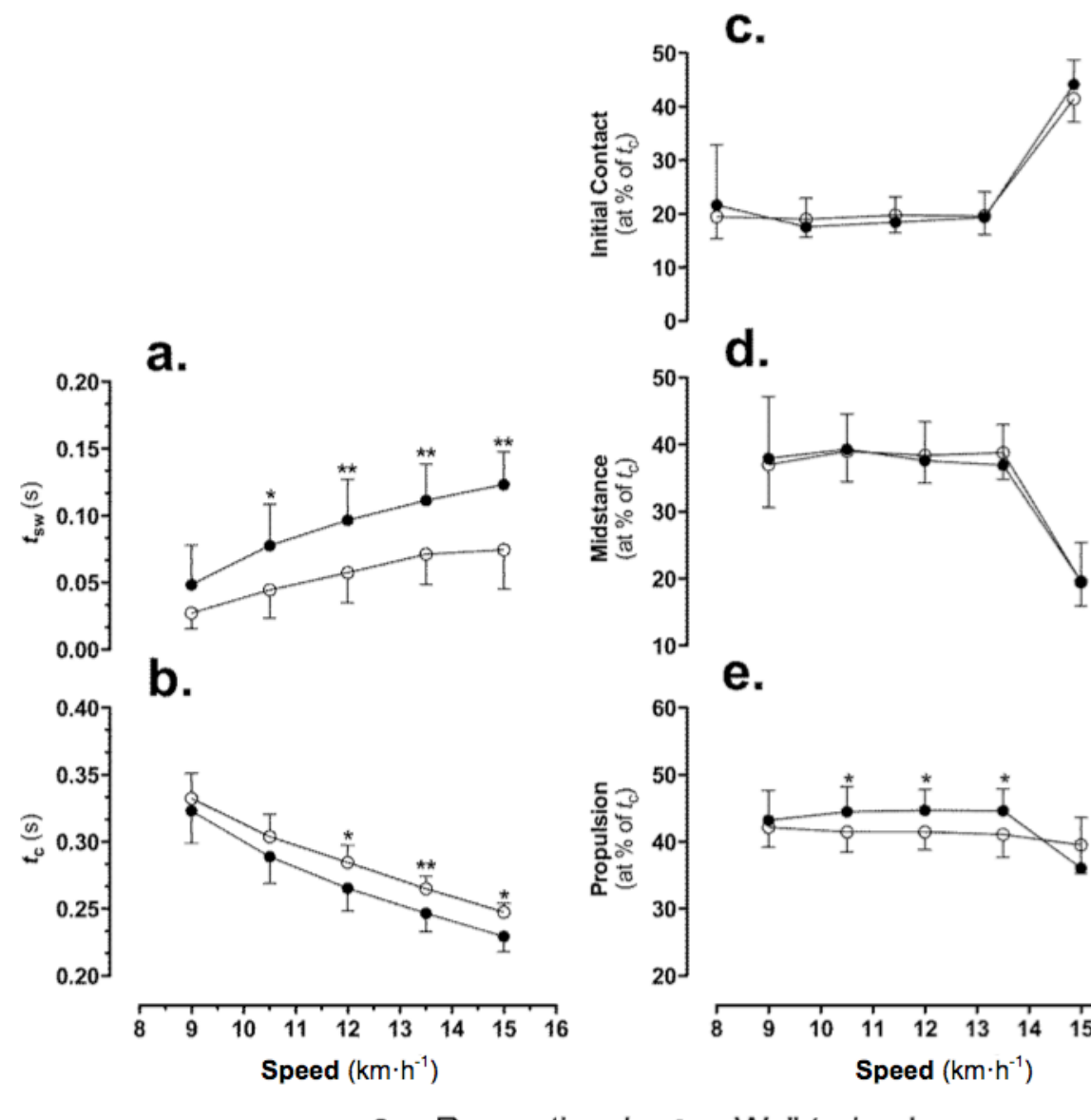

d.

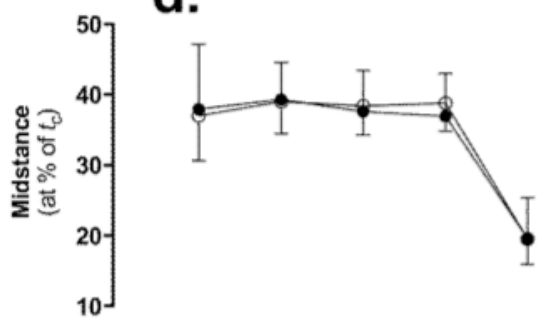

e.

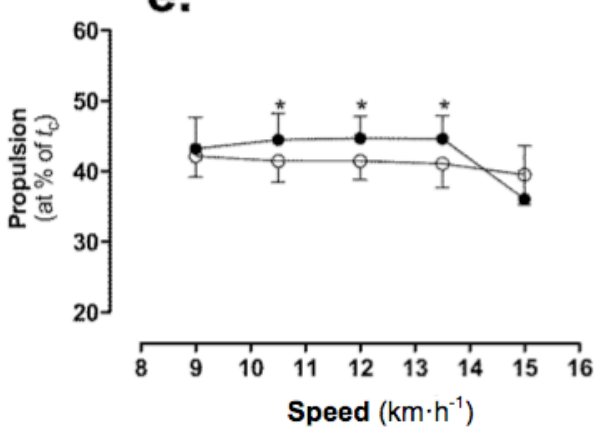

$\multimap$ Recreational $\bullet-$ Well-trained

Figure 3. Ground contact time $\left(t_{\mathrm{c}}\right)$, swing time $\left(t_{\mathrm{sw}}\right)$ and the percentage of the ground contact time $\left(\%\right.$ of $\left.t_{\mathrm{c}}\right)$ at which the different subphases of stance phase (initial contact, midstance and propulsion). Significantly different when compared to recreational runners: ${ }^{*} P<0.05 ;{ }^{* *} P<0.01$

Additionally, the recreational runners exhibited shorter stride lengths at $12 \mathrm{~km} \cdot \mathrm{h}^{-1}, 13.5 \mathrm{~km} \cdot \mathrm{h}^{-}$ ${ }^{1}\left(P<0.05\right.$, moderate ES) and $15 \mathrm{~km} \cdot \mathrm{h}^{-1}(P<0.01$, large ES $)$, lower stride frequencies at 12 $\mathrm{km} \cdot \mathrm{h}^{-1}, 13.5 \mathrm{~km} \cdot \mathrm{h}^{-1}(P<0.05$, moderate ES $)$ and $15 \mathrm{~km} \cdot \mathrm{h}^{-1}(P<0.01$, large ES $)$ and lower stride angles at $10.5 \mathrm{~km} \cdot \mathrm{h}^{-1}(P<0.05), 12 \mathrm{~km} \cdot \mathrm{h}^{-1}, 13.5 \mathrm{~km} \cdot \mathrm{h}^{-1}$ and $15 \mathrm{~km} \cdot \mathrm{h}^{-1}(P<0.01$, large ES) than the well-trained runners (Figure 4). 


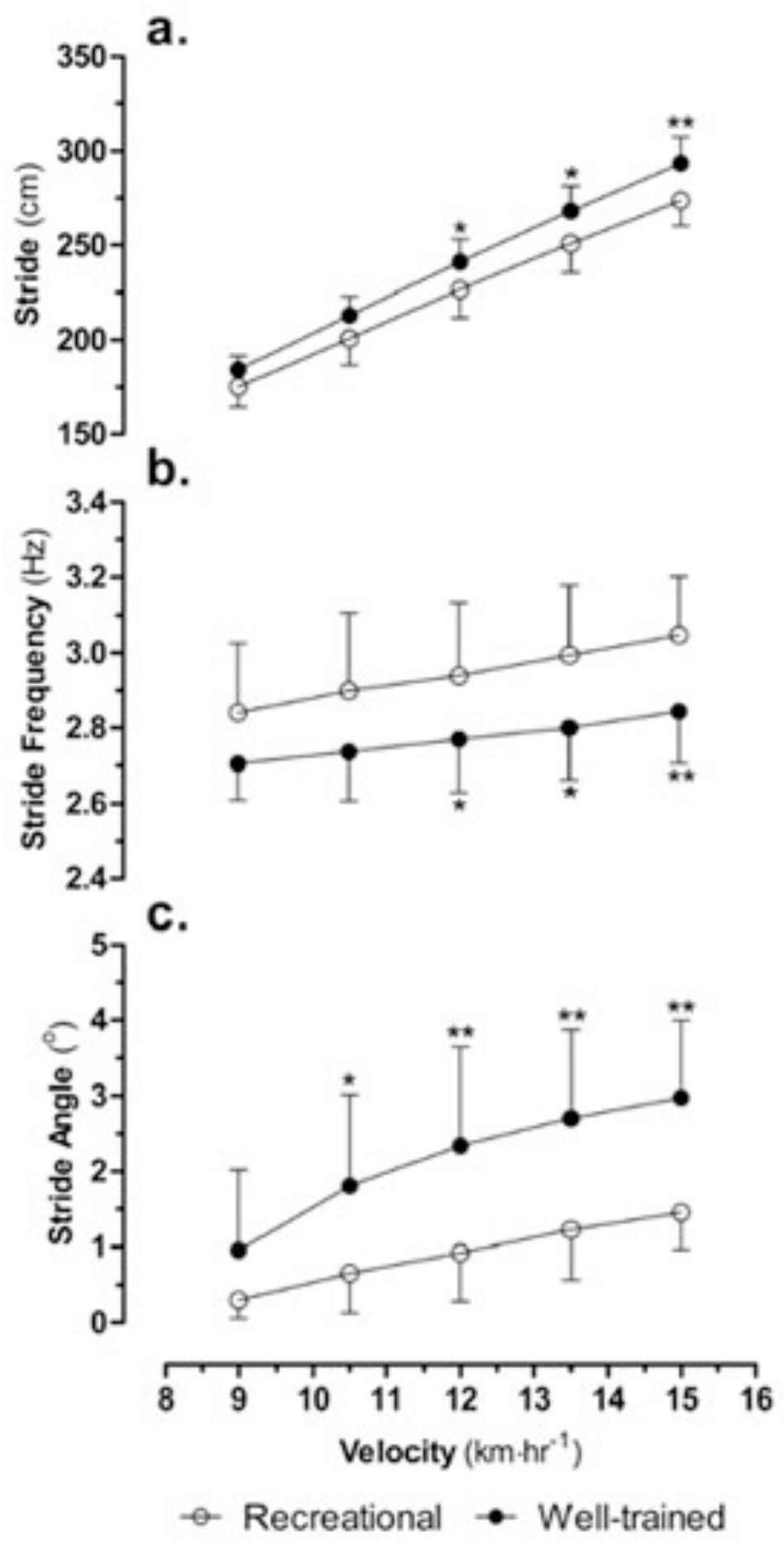

Figure 4. Stride length, stride frequency and stride angle values measured in the recreational and the welltrained runners at different speeds. Significantly different when compared to recreational runners: ${ }^{*} P<0.05$; ${ }^{* *} P<0.01$

RE was positively correlated with $t_{\mathrm{c}}$ at $12 \mathrm{~km} \cdot \mathrm{h}^{-1}$ and $13.5 \mathrm{~km} \cdot \mathrm{h}^{-1}(P<0.05)$ and with the stride frequency at $9 \mathrm{~km} \cdot \mathrm{h}^{-1}, 10.5 \mathrm{~km} \cdot \mathrm{h}^{-1}, 12 \mathrm{~km} \cdot \mathrm{h}^{-1}, 13.5 \mathrm{~km} \cdot \mathrm{h}^{-1}$ and $15 \mathrm{~km} \cdot \mathrm{h}^{-1}(P<0.01)$. On the other hand, RE correlated negatively with $t_{\mathrm{sw}}$ at $10.5 \mathrm{~km} \cdot \mathrm{h}^{-1}(P<0.05), 12 \mathrm{~km} \cdot \mathrm{h}^{-1}(P<0.01)$, $13.5 \mathrm{~km} \cdot \mathrm{h}^{-1}(P<0.001)$ and $15 \mathrm{~km} \cdot \mathrm{h}^{-1}(P<0.05)$ and with the stride length at $9 \mathrm{~km} \cdot \mathrm{h}^{-1}, 10.5$ $\mathrm{km} \cdot \mathrm{h}^{-1}, 12 \mathrm{~km} \cdot \mathrm{h}^{-1}(P<0.01)$ and $13.5 \mathrm{~km} \cdot \mathrm{h}^{-1}(P<0.001)$. Similarly, RE was also negatively correlated with the stride angle at $10.5 \mathrm{~km} \cdot \mathrm{h}^{-1}(P<0.05), 12 \mathrm{~km} \cdot \mathrm{h}^{-1}, 13.5 \mathrm{~km} \cdot \mathrm{h}^{-1}(P<0.01)$ and $15 \mathrm{~km} \cdot \mathrm{h}^{-1}(P<0.05)$, and with the propulsive subphase at $10.5 \mathrm{~km} \cdot \mathrm{h}^{-1}(P<0.05)$. 
Santos-Concejero, J.; Granados, C.; Irazusta, J., Bidaurrazaga-Letona, I.; Zabala-Lili, J.; Tam, N., \& Gil, S.M. (2014). Influence of the biomechanical variables of the gait cycle in running economy. RICYDE. Revista internacional de ciencias del deporte, 36(10), 95-108 http://dx.doi.org/10.5232/ricyde2014.03601

Table 2. Interrelationships between biomechanical variables as well as running performance according 10-km race time and running economy at different speeds.

\begin{tabular}{|c|c|c|c|c|c|}
\hline \multirow[b]{2}{*}{ Biomechanical variables } & \multicolumn{5}{|c|}{ Running economy at $\left(\mathrm{km} \cdot \mathrm{h}^{-1}\right)$} \\
\hline & 9 & 10.5 & 12 & 13.5 & 15 \\
\hline Contact time & -0.08 & 0.15 & $0.45^{*}$ & $0.45^{*}$ & 0.36 \\
\hline Swing time & -0.35 & $-0.46^{*}$ & $-0.61^{* *}$ & $-0.65^{* * *}$ & $-0.43^{*}$ \\
\hline Stride length & $-0.61^{* * *}$ & $-0.52^{* *}$ & $-0.56^{* *}$ & $-0.65^{* * *}$ & -0.39 \\
\hline Stride frequency & $0.63^{* * *}$ & $0.56^{* *}$ & $0.56^{* *}$ & $0.65^{* *}$ & 0.37 \\
\hline Stride angle & -0.34 & $-0.44^{*}$ & -0.60 ** & $-0.62^{* * *}$ & $-0.42^{*}$ \\
\hline Contact subphase & 0.02 & 0.13 & 0.25 & 0.10 & 0.00 \\
\hline Midstance subphase & 0.08 & 0.19 & -0.07 & 0.13 & 0.11 \\
\hline Propulsive subphase & -0.21 & $-0.40^{*}$ & -0.22 & -0.26 & -0.13 \\
\hline $10-\mathrm{km}$ race time & $0.57^{* *}$ & $0.63^{* *}$ & $0.66^{* * *}$ & $0.79^{* * * *}$ & $0.57^{* *}$ \\
\hline
\end{tabular}

Significant correlations: ${ }^{*} P<0.05 ;{ }^{* *} P<0.01 ;{ }^{* * *} P<0.001$

Finally, running performance according to the best $10-\mathrm{km}$ race time was positively correlated with RE at $9 \mathrm{~km} \cdot \mathrm{h}^{-1}, 10.5 \mathrm{~km} \cdot \mathrm{h}^{-1}(P<0.01), 12 \mathrm{~km} \cdot \mathrm{h}^{-1}, 13.5 \mathrm{~km} \cdot \mathrm{h}^{-1}(P<0.001)$ and $15 \mathrm{~km} \cdot \mathrm{h}^{-1}$ $(P<0.01)$, whereas neither the contact subphase nor the midstance subphase showed any significant correlation with RE (Table 2).

\section{Discussion}

The first finding of this study was that there were significant biomechanical differences that discriminated between the recreational and well-trained runners at various submaximal speeds, in addition to all traditional maximal variables (such as $V \mathrm{O}_{2 \max }$ and PTS) and RE.

The well-trained runners were more economical than the recreational runners at all submaximal running speeds in this study (Figure 2). This is in agreement with previous studies, which have reported better RE in elite runners compared to good runners at a set speed (Nummela et al., 2007). Further, Helgerud et al. (2010) described that RE is proportional to body mass allometrically scaled. When $V \mathrm{O}_{2}$ was normalized to body mass ${ }^{0.75}$ in our study the differences were accentuated between both groups. This finding suggests that other factors may contribute to differences in RE and not only anthropometrical variables (Saunders, Pyne, Telford \& Hawley, 2004).

Accordingly, we found that biomechanical variables were significantly different at speeds above $9 \mathrm{~km} \cdot \mathrm{h}^{-1}$ (Figures $3 \& 4$ ). In this regard, this study confirms that well-trained runners present particular running patterns characterized by longer stride lengths, lower stride frequencies, lower $t_{\mathrm{c}}$ and higher $t_{\mathrm{sw}}$ that enable effective and efficient energy use per stride. These findings are in agreement with previous studies investigating male and female runners and trained and untrained runners (Anderson, 1996; Cavanagh \& Williams, 1982; Chapman et al., 2011; Kaneko et al., 1985, Tartaruga et al., 2012). Previous researchers have found that self-selected stride lengths demand less oxygen at a given speed compared to other predetermined stride lengths (Hogberg, 1952). Further, well-trained runners acquire an optimal stride length and stride frequency over time based on perceived exertion (Saunders et 
Santos-Concejero, J.; Granados, C.; Irazusta, J., Bidaurrazaga-Letona, I.; Zabala-Lili, J.; Tam, N., \& Gil, S.M. (2014). Influence of the biomechanical variables of the gait cycle in running economy. RICYDE. Revista internacional de ciencias del deporte, 36(10), 95-108 http://dx.doi.org/10.5232/ricyde2014.03601

al., 2004) and may also be physiologically adapted to some stride lengths and frequencies at particular speeds (Anderson, 1996). Duggan and Bhat (2005) suggested that these biomechanical differences may be a result of an increased flexibility and eccentric muscle strength in the well-trained groups.

Greater flexibility and eccentric muscle strength may be revealed by stride angle. Stride angle comprises of stride length and the maximum height the foot reaches during swing phase. Both features are biomechanically driven by the extent of hip, knee and ankle flexionextension. The well-trained runners in this study exhibited significantly greater stride angles than the recreational runners (Figure 4). This difference in stride angle is exemplary of the ability for well-trained runners to efficiently maximize $t_{\mathrm{sw}}$ with greater hip, knee and ankle flexion and minimize $t_{\mathrm{c}}$ with effective energy transfer during the propulsion subphase as found in the well-trained runners in this study.

These phenomena may be depicted in well-trained athletes as the ability of the foot to reach the glutes. Many coaches and keen athletic observers have note this as a flick or buttkick. However, this has not been well described, as the analysis of swing phase biomechanics during running is often overlooked in importance when compared to ground contact. This flick or buttkick during swing phase appears to be associated with the ability for the athlete to efficiently transfer energy generated from minimal ground contact to ground contact and drive the body forward (Novacheck, 1998).

In this study both $t_{\mathrm{sw}}$ and stride angle were strongly associated with RE at the set speeds (Table 2). Kram and Taylor (1990) alluded that the work done against the environment may be less important than the ability for the muscles and tendons to lift and accelerate the body and limbs. As it has been documented, a majority of muscles are active during the swing phase, most particularly in the acceleration of the limbs and preparation for ground contact (Chumanov, Heiderscheit \& Thelen, 2011). Thus, it appears that the swing phase and stride angle may be an effective discriminator of efficient gait patterns and should be analysed further in its contribution to the economy of motion.

Variables related to the ground contact phase of the gait cycle have been reported to be the major determinants of metabolic demand (Anderson, 1996; Kyröläinen et al., 2001, Saunders et al., 2004). For example, propulsion subphase during the ground contact was experienced significantly later in the well-trained runners than in the recreational runners at certain speeds (Figure 3). The propulsion subphase is where force is applied from the lower limbs to the ground to obtain forward horizontal displacement during running. Novacheck (1998) describes that the percentage of the gait cycle at which toe off occurs depends not only on the speed, but also on the athletic ability of the runner (Novacheck, 1998). Therefore, these differences between groups appear to be an indicator of the superior athletic ability of the well-trained runners when compared to the recreational runners. In this regard, the significant correlation found in this study between RE and the percentage at which the propulsive subphase occurs, may imply that differences in the propulsive subphase kinetics can influence the energy cost of running. However, the lack of ground contact forces analysis in this study impedes to speculate for a possible explanation for this correlation.

Lastly, an efficient RE was also associated with faster $10-\mathrm{km}$ race time (Table 2). This finding is evidence that running performance according to $10-\mathrm{km}$ race time is associated with an efficient RE. Subsequently, faster race times may be, at least in part, a result of better RE that may be facilitated by the various biomechanical changes previously discussed, such as, lower $t_{\mathrm{c}}$, increased $t_{\mathrm{sw}}$, longer stride lengths, lower stride frequencies and higher stride angles. Further research simultaneously investigating the musculotendinous involvement, in-depth 
Santos-Concejero, J.; Granados, C.; Irazusta, J., Bidaurrazaga-Letona, I.; Zabala-Lili, J.; Tam, N., \& Gil, S.M. (2014). Influence of the biomechanical variables of the gait cycle in running economy. RICYDE. Revista internacional de ciencias del deporte, 36(10), 95-108 http://dx.doi.org/10.5232/ricyde2014.03601

biomechanical analysis and complex multivariate statistics are required, in order to elucidate the physiological and biomechanical changes that occur to achieve optimal RE and improved performance.

\section{Conclusion}

Part of the differences observed between RE in recreational and well-trained athletes were found to be a result of differing athletic ability and biomechanical features. Our results suggest that particular running patterns characterized by longer stride lengths, lower stride frequencies, greater stride angles, lower $t_{\mathrm{c}}$, higher $t_{\mathrm{sw}}$ and later propulsion suphases during the ground contact enable an effective and efficient energy use per stride. Therefore, changes in the biomechanical running technique can influence the energy cost of running and lead to improve performance.

\section{Aknowledgments}

This study was supported by the Basque Government scholarship (ref. BFI08.51) to Jordan Santos-Concejero and by the Department of Physical Education and Sport of the University of the Basque Country (UPV/EHU).

\section{References}

Anderson, T. (1996). Biomechanics and running economy. Sports Medicine, 22, 76-89. http://dx.doi.org/10.2165/00007256-199622020-00003

Åstrand, P.O.; Rodahl, K.; Dahl, H., \& Strommer, S. (1986). Textbook of work physiology: physiological bases of exercise. New York: McGraw Hill.

Bergh, U.; Sjödin, B.; Forsberg, A., \& Svedenhag, J. (1991). The relationship between body mass and oxygen uptake during running in humans. Medicine \& Science in Sports \& Exercise, 23, 205-211. http://dx.doi.org/10.1249/00005768-199102000-00010

Bosco, C.; Montanari, G.; Ribacchi, R.; Giovenali, P.; Latteri, F.; Lachelli, G.; Faina, M.; Colli, R.; Dal Monte, A., \& La Rosa, M. (1987). Relationship between the efficiency of muscular work during jumping and the energetic. European Journal of Applied Physiology and Occupational Physiology, 56, 138-143. http://dx.doi.org/10.1007/BF00640636

Bransford, D.R., \& Howley, E.T. (1977). Oxygen cost of running in trained and untrained men and women. Medicine and Science in Sport, 9, 41-44.

Cavanagh, P.R., \& Williams, K.R. (1982). The effect of stride length variation on oxygen uptake during distance running. Medicine \& Science in Sports \& Exercise, 14, 30-35. http://dx.doi.org/10.1249/00005768-198201000-00006

Chapman, R.F.; Laymon, A.S.; Wilhite, D.P.; McKenzie, J.M.; Tanner, D.A., \& Stager, J.M. (2012). Ground contact time as an indicator of metabolic cost in elite distance runners. Medicine \& Science in Sports \& Exercise, 4, 917-92. http://dx.doi.org/10.1249/MSS.0b013e3182400520

Cheng, B.; Kuipers, H.; Snyder, A.C.; Keizer, H.A.; Jeukendrup, A., \& Hesselink, M. (1992). A new approach for the determination of ventilatory and lactate thresholds. International Journal of Sports Medicine, 13, 518-522. http://dx.doi.org/10.1055/s-2007-1021309

Chumanov, E.S.; Heiderscheit, B.C., \& Thelen, D.G. (2011). Hamstring musculotendon dynamics during stance and swing phases of high-speed running. Medicine \& Science in Sports \& Exercise, 43, 525-532. http://dx.doi.org/10.1249/MSS.0b013e3181f23fe8 
Santos-Concejero, J.; Granados, C.; Irazusta, J., Bidaurrazaga-Letona, I.; Zabala-Lili, J.; Tam, N., \& Gil, S.M. (2014). Influence of the biomechanical variables of the gait cycle in running economy. RICYDE. Revista internacional de ciencias del deporte, 36(10), 95-108 http://dx.doi.org/10.5232/ricyde2014.03601

Cohen, J. Statistical power analysis for the behavioral sciences. Hillsdale: Lawrence Erlbaum Associates, 1998.

Conley, D.L., \& Krahenbuhl, G.S. (1980). Running economy and distance running performance of highly trained athletes. Medicine \& Science in Sports \& Exercise, 12, 357-360.

Daniels, J., \& Daniels, N. (1982). Running economy of elite male and elite female runners. Medicine \& Science in Sports \& Exercise, 24, 483-489.

Debaere, S.; Jonkers, I., \& Delecluse, C. (2013). The contribution of step characteristics to sprint running performance in high-level male and female athletes. Journal of Strength \& Conditioning Research, 27, 116-124.

http://dx.doi.org/10.1519/JSC.0b013e31825183ef

Di Pampero, P.E.; Atchou, G.; Brückner, J.C., \& Moia, C. (1986). The energetics of endurance running. European Journal of Applied Physiology and Occupational Physiology, 55, 259-266.

http://dx.doi.org/10.1007/BF02343797

Duggan, S.A., \& Bhat, K.P. (2005). Biomechanics and Analysis of Running Gait. Physical Medicine \& Rehabilitation Clinics of North America, 16, 603-621. http://dx.doi.org/10.1016/j.pmr.2005.02.007

Foster, C., \& Lucia, A. (2007). Running economy: the forgotten factor in elite performance. Sports Medicine, 37, 316-319.

http://dx.doi.org/10.2165/00007256-200737040-00011

Gregor, R.J., \& Kirkendall, D. (1978). Performance efficiency of world class female marathon runners. In E. Asmussen \& K. Jörgensen (Eds.), Biomechanics VI-B. (pp. 40-45). Baltimore: University Park Press.

Helgerud, J.; Engen, L.C.; Wisloff, U., \& Hoff, J. (2001). Aerobic endurance training improves soccer performance. Medicine \& Science in Sports \& Exercise, 33, 19251931. http://dx.doi.org/10.1097/00005768-200111000-00019

Helgerud, J.; Støren, O., \& Hoff, J. (2010). Are there differences in running economy at different speeds for well-trained distance runners? European Journal of Applied Physiology, 108, 1099-1105.

http://dx.doi.org/10.1007/s00421-009-1218-z

Hogberg, P. (1952). Length of stride, stride frequency, "flight" period and maximum distance between the feet during running with different speeds. Arbeitsphysiologie, $14,431-436$.

Hopkins, W.G.; Marshall, S.W.; Batterham, A.M., \& Hanin J. (2009). Progressive statistics for studies in sports medicine and exercise science. Medicine \& Science in Sports \& Exercise, 41, 3-13.

http://dx.doi.org/10.1249/MSS.0b013e31818cb278

Joyner, M.J. (1991). Modeling: optimal marathon performance on the basis of physiological factors. Journal of Applied Physiology, 70, 683-687.

Kaneko, M.; Ito, A.; Fuchimoto, T.; Shishikura, Y., \& Toyooka J. (1985). Influence of running speed of the mechanical efficiency of sprinters and distance runners. In D.A. Winter, R.W. Norman, R.P. Wells, C.K. Heyes \& A.E. Patla (Eds.), Biomechanics IX-B (pp. 307-312). Champaign: Human Kinetics.

Karp, J.R. (2010). Strength Training For Distance Running: A Scientific Perspective. Strength and Conditioning Journal, 32, 83-86.

http://dx.doi.org/10.1519/SSC.0b013e3181df195b 
Santos-Concejero, J.; Granados, C.; Irazusta, J., Bidaurrazaga-Letona, I.; Zabala-Lili, J.; Tam, N., \& Gil, S.M. (2014). Influence of the biomechanical variables of the gait cycle in running economy. RICYDE. Revista internacional de ciencias del deporte, 36(10), 95-108 http://dx.doi.org/10.5232/ricyde2014.03601

Krahenbuhl, G.S., \& Pangrazi, R.P. (1983). Characteristics associated with running performance in young boys. Medicine \& Science in Sports \& Exercise, 15, 486-490. http://dx.doi.org/10.1249/00005768-198315060-00008

Kram, R., \& Taylor, C.R. (1990). Energetics of running: a new perspective. Nature, 346, 265-267. http://dx.doi.org/10.1038/346265a0

Kyröläinen, H.; Belli, A., \& Komi, P.V. (2001). Biomechanical factors affecting running economy. Medicine \& Science in Sports \& Exercise, 33, 1330-1337. http://dx.doi.org/10.1097/00005768-200108000-00014

Levine, B.D. (2008). VO2max: what do we know, and what do we still need to know? Journal of Physiology, 586, 25-34. http://dx.doi.org/10.1113/jphysiol.2007.147629

Lucia, A.; Esteve-Lanao, J.; Oliván, J.; Gómez-Gallego, F.; San Juan, A.F.; Santiago, C.; Pérez, M.; Chamorro-Viña, C., \& Foster, C. (2006). Physiological characteristics of the best Eritrean runners-exceptional running economy. Applied Physiology, Nutrition and Metabolism, 31, 530-540. http://dx.doi.org/10.1139/h06-029

Maldonado, S.; Mujika, I., \& Padilla, S. (2002). Influence of body mass and height on the energy cost of running in highly trained middle- and long-distance runners. International Journal of Sports Medicine, 23, 268-272.

http://dx.doi.org/10.1055/s-2002-29083

Maldonado-Martín, S.; Mujika, I., \& Padilla, S. (2004). Physiological variables to use in the gender comparison in highly trained runners. Journal of Sports Medicine \& Physical Fitness, 44, 8-14.

Mayhew, J.L. (1997). Oxygen cost and energy expenditure of running in trained runners. British Journal of Sports Medicine, 11, 116-121.

http://dx.doi.org/10.1136/bjsm.11.3.116

Novacheck, T.F. (1998). Review paper: the biomechanics of running. Gait \& Posture, 7, 77-95. http://dx.doi.org/10.1016/S0966-6362(97)00038-6

Nummela, A.; Keränen, T., \& Mikkelsson, L. (2007). Factors related to top running speed and economy. International Journal of Sports Medicine, 28, 655-661. http://dx.doi.org/10.1055/s-2007-964896

Pate, R.R.; Macera, C.A.; Bailey, S.P.; Bartoli, W.P., \& Powell, K.E. (1992). Physiological, anthropometric, and training correlates of running economy. Medicine \& Science in Sports \& Exercise, 24, 1128-1133.

http://dx.doi.org/10.1249/00005768-199210000-00010

Saunders, P.U.; Pyne, D.B.; Telford, R.D., \& Hawley, J.A. (2004). Factors affecting running economy in trained distance runners. Sports Medicine, 34, 456-485. http://dx.doi.org/10.2165/00007256-200434070-00005

Tartaruga, M.P.; Brisswalter, J.; Peyré-Tartaruga, L.A.; Avila, A.O.; Alberton, C.L.; Coertjens, M.; Cadore, E.L.; Tiggemann, C.L.; Silva, E.M., \& Kruel LF. (2012). The relationship between running economy and biomechanical variables in distance runners. Research Quarterly for Exercise and Sport. 3, 367-375.

Weyand, P.G.; Sternlight, D.B.; Bellizzi, M.J., \& Wright, S. (2000). Faster top running speeds are achieved with greater ground forces not more rapid leg movements. Journal of Applied Physiology, 89, 1991-1999.

Yoshida, T. (1984). Effect of exercise duration during incremental exercise on the determination of anaerobic threshold and the onset of blood lactate accumulation. European Journal of Applied Physiology \& Occupational Physiology, 53, 196-199. http://dx.doi.org/10.1007/BF00776589

Yuhasz, M.S. (1974). Physical fitness Manual. London: University of Western Ontario. 